\title{
植物光合作用叶肉导度及主要限制因素研究进展
}

\author{
韩吉梅 ${ }^{1}$ 张旺锋 ${ }^{1}$ 熊栋梁 ${ }^{2}$ Jaume FLEXAS ${ }^{2}$ 张亚黎 $^{*}$ \\ 1 石河子大学农学院, 新疆生产建设兵团绿洲生态农业重点实验室, 新疆石河子, 832003 , 中国; ${ }^{2} 巴$ 利阿里群岛大学, 地中海植物生物学实验室, 帕尔 \\ 马市, 巴利阿里群岛, 07122, 西班牙
}

\begin{abstract}
摘 要 叶肉导度 $\left(g_{\mathrm{m}}\right)$ 被用来衡量 $\mathrm{CO}_{2}$ 从植物叶片气孔下腔到叶绿体羧化位点的传输效率, 其主要受解剖结构和生化因素的 调控。近年来, $g_{\mathrm{m}}$ 的研究在光合作用领域受到普遍关注; 光合速率的限制因素已不再简单地划分为气孔限制和非气孔限制, 而 需要从气孔限制、叶肉限制和羧化限制 3 个限制因素开展研究工作。该文分析了植物细胞壁、细胞膜、细胞质、叶绿体膜和 叶绿体基质对 $g_{\mathrm{m}}$ 的调控机制, 指出细胞壁厚度以及面向细胞间隙的叶绿体面积 $\left(S_{\mathrm{c}}\right)$ 是影响 $g_{\mathrm{m}}$ 的重要结构因素。阐述了水孔蛋 白和碳酸酩酶参与的生化过程对 $g_{\mathrm{m}}$ 的调控机制。同时, 对外界环境因素, 如温度、光强、干旱、氮等对 $g_{\mathrm{m}}$ 的调控机制进行了 总结。在此基础上，探讨了 $g_{\mathrm{m}}$ 与水力导度的耦合关系。最后对 $g_{\mathrm{m}}$ 研究中的科学问题进行了展望。
\end{abstract}

关键词 光合作用; $\mathrm{CO}_{2}$ 传输; 叶肉导度; 解剖结构; 生化因素; 环境变化; 水力导度

引用格式: 韩吉梅, 张旺锋, 熊栋梁, Flexas J, 张亚黎 (2017). 植物光合作用叶肉导度及主要限制因素研究进展. 植物生态学报, 41, 914-924. doi: $10.17521 /$ cjpe. 2016.0337

\section{Mesophyll conductance and its limiting factors in plant leaves}

\author{
HAN Ji-Mei ${ }^{1}$, ZHANG Wang-Feng ${ }^{1}$, XIONG Dong-Liang ${ }^{2}$, FLEXAS Jaume ${ }^{2}$, and ZHANG Ya-Li ${ }^{1 *}$ \\ ${ }^{1}$ Shihezi University, Agricultural College, The Key Laboratory of Oasis Eco-agriculture, Xinjiang Production and Construction Group, Shihezi, Xinjiang \\ 832003, China; and ${ }^{2}$ Universitat de les Illes Balears, Research Group in Plant Biology Under Mediterranean Conditions, Palma de Mallorca 07122, Illes \\ Balears, Spain
}

\begin{abstract}
Mesophyll conductance $\left(g_{\mathrm{m}}\right)$ represents the $\mathrm{CO}_{2}$ diffusion facility from sub-stomatal internal cavities to carboxylation sites in chloroplasts, and the variation of $g_{\mathrm{m}}$ across genotypes as well as environmental conditions is expected to be related to the anatomical structures and biochemical properties of leaves. In recent years, the variation of $g_{\mathrm{m}}$ has attracted wide attention. The limiting factors in photosynthetic rate are no longer divided simply into stomatal limitation and non-stomatal limitation, but splitted in stomatal limitation, mesophyll limitation and carboxylation limitation. In this review, we summarize the potential influences of cell wall, cell membrane, cytoplasm, chloroplast envelope and stroma on $g_{\mathrm{m}}$, and indicate that cell wall thickness and the surface area of chloroplast exposed to intercellular air space $\left(S_{\mathrm{c}}\right)$ are the most important factors influencing the $g_{\mathrm{m}}$. We also analyze the probable effects of biochemical process related with aquaporins and carbonic anhydrase on $g_{\mathrm{m}}$. Meanwhile, the regulation mechanisms of long- and short-term environment changes (including temperature, light intensity, drought, and nutrients) on $g_{\mathrm{m}}$ are also summarized. The relationship between $g_{\mathrm{m}}$ and hydraulic conductance $\left(K_{\text {leaf }}\right)$ is debated. Finally, we discuss the scientific problems related with $g_{\mathrm{m}}$.
\end{abstract}

Key words photosynthesis; $\mathrm{CO}_{2}$ diffusion; mesophyll conductance; anatomical structure; biochemical factor; environmental change; hydraulic conductance

Citation: Han JM, Zhang WF, Xiong DL, Flexas J, Zhang YL (2017). Mesophyll conductance and its limiting factors in plant leaves. Chinese Journal of Plant Ecology, 41, 914-924. doi: 10.17521/cjpe.2016.0337

光合作用是绿色植物利用光能, 把 $\mathrm{CO}_{2}$ 和 $\mathrm{H}_{2} \mathrm{O}$ 合成有机物, 同时释放 $\mathrm{O}_{2}$ 的生理过程。 $\mathrm{CO}_{2}$ 首先从 外界大气扩散到叶片表层, 然后穿过气孔到达气孔 下腔, 最后到达叶绿体羧化位点由羧化酶进行同 化。早期一些研究认为 $\mathrm{CO}_{2}$ 从气孔下腔到叶绿体羧
化位点的扩散阻力 $\left(r_{\mathrm{m}}\right.$, 其倒数为叶肉导度 $\left(g_{\mathrm{m}}\right)$ 趋近于 无穷小, 从而将 $\mathrm{CO}_{2}$ 对光合速率的限制简化为气孔 和非气孔(羧化)两个因素。基于这种假设, 在 Farquhar-von-Caemmerer-Berry (FvCB)光合模型中, 叶绿体羧化位点的 $\mathrm{CO}_{2}$ 浓度 $\left(C_{\mathrm{c}}\right)$ 采用胞间 $\mathrm{CO}_{2}$ 浓度

收稿日期Received: 2016-11-03 接受日期Accepted: 2017-04-05

* 通信作者Author for correspondence (E-mail: zhangyali_cn@foxmail.com) 
$\left(C_{\mathrm{i}}\right)$ 替代(Farquhar et al., 1980)。随后的一些研究发 现, 植物的 $g_{\mathrm{m}}$ 并不是无穷大(Evans et al., 1986; von Caemmerer \& Evans, 1991; Harley et al., 1992; Evans \& von Caemmerer, 1996)。不同植物的 $g_{\mathrm{m}}$ 存在差异, 而且 $g_{\mathrm{m}}$ 也会随环境的变化而做出适应性的调整 (Flexas et al., 2008，2012)。研究表明, $g_{\mathrm{m}}$ 对温度 (Bernacchi et al., 2002; Flexas \& Diaz-Espejo, 2015)、蓝光强度(Loreto et al., 2009)、水分亏缺 (Flexas et al., 2002; Miyazawa et al., 2008; Han et al., 2016)等外界环境条件的改变均会做出相应的响 应。因此, $g_{\mathrm{m}}$ 被认为是除气孔限制和羧化限制外的 光合效率第三个限制因素, 并认为与气孔导度 $\left(g_{\mathrm{s}}\right)$ 同等重要(Flexas et al., 2012)。通常, 依据FvCB光合 模型的 $\mathrm{CO}_{2}$ 响应曲线 $\left(A_{\mathrm{N}}-C_{\mathrm{i}}\right.$ 曲线)拟合方法, 不考虑 $g_{\mathrm{m}}$ 的影响, 往往导致拟合出的光合参数存在偏差。 因此, 有研究从考虑 $g_{\mathrm{m}}$ 影响的角度, 对 $\mathrm{FvCB}$ 光合模 型 $A_{\mathrm{N}}-C_{\mathrm{i}}$ 曲线拟合方法进行了修正, 例如 Ethier和 Livingston (2004)对Farquhar等(1980)的光合模型的 非直角双曲线模型进行优化, 对 $A_{\mathrm{N}}-C_{\mathrm{i}}$ 曲线进行拟 合得到 $g_{\mathrm{m}}$, 这种方法降低了光合参数对 $g_{\mathrm{m}}$ 的敏感 度。Sharkey等(2007)介绍了一种非线性曲线拟合方 法对 $A_{\mathrm{N}}-C_{\mathrm{i}}$ 曲线进行拟合。以上拟合方法均假设 $g_{\mathrm{m}}$ 不受 $C_{\mathrm{i}}$ 影响且光系统II中光吸收系数为常数。为避 免以上问题, Moualeu-Ngangue等(2016)重新提出了 一种 $A_{\mathrm{N}}-C_{\mathrm{i}}$ 曲线拟合方法。除 $A_{\mathrm{N}}-C_{\mathrm{i}}$ 曲线拟合 $g_{\mathrm{m}}$ 之外, 气体交换和叶绿素荧光同步测定法与气体交换和同 位素同步测定法也可估算 $g_{\mathrm{m}}$, 但3种方法均存在一 定的缺陷。一般而言, 外界环境通过影响叶片内部 物理和(或)生化因素进而影响 $g_{\mathrm{m}}$ 。同时, 由于 $g_{\mathrm{m}}$ 的变 化只影响叶片内 $\mathrm{CO}_{2}$ 的运输而不涉及水分散失, 因 此有研究提出, $g_{\mathrm{m}}$ 是实现植物叶片光合速率和水分 利用效率同步提高的生理位点。

\section{1 叶片结构和生化因素对叶肉导度的影响}

在组织细胞水平, $g_{\mathrm{m}}$ 的影响因素主要包括结构 因素和生化因素。在结构层面, $\mathrm{CO}_{2}$ 在叶肉细胞中的 扩散依次经过细胞间隙、细胞壁、细胞膜、细胞质、 叶绿体膜和叶绿体基质等(图1, 图2)。 $\mathrm{CO}_{2}$ 在这些扩 散过程中会受到层层阻碍, 从而影响 $g_{\mathrm{m}}$ 。在生化层 面, 在叶片传输过程中 $\mathrm{CO}_{2}$ 可以被碳酸酐酶 $(\mathrm{CA})$ 催 化转变成 $\mathrm{HCO}_{3}^{-}$进行扩散, 同时水孔蛋白(AQPs)也 可以介导 $\mathrm{CO}_{2}$ 的跨膜运输。实际上, 生化层面和结构
层面两者密不可分, $\mathrm{AQPs}$ 存在于生物膜上, CA主要 存在于叶绿体基质中。

\section{1 结构层面的限制}

有研究表明, $g_{\mathrm{m}}$ 主要由叶片解剖结构决定(Niinemets et al., 2009; Tosens et al., 2012a; Tomás et al., 2013)。大量研究认为面向细胞间隙的叶绿体面积 $\left(S_{\mathrm{c}}\right)$ 与叶片总面积 $(S)$ 的比值 $\left(S_{\mathrm{c}} / S\right)$ (von Caemmerer \& Evans, 1991; Evans et al., 1994; Pakatas et al., 2003; Flexas et al., 2012)和细胞壁厚度(Hanba et al., 1999, 2002; Terashima et al., 2011) 是影响 $g_{\mathrm{m}}$ 的主要结构 因素。

有研究用一维气体扩散模型定量分析不同组 织细胞结构对 $\mathrm{CO}_{2}$ 扩散的重要程度 (Niinemets \& Reichstein, 2003a; Tosens et al., 2012a; Tomás et al., 2013)。 $g_{\mathrm{m}}$ 被分为气相导度 $\left(g_{\mathrm{ias}}\right)$ 和液相导度 $\left(g_{\mathrm{liq}}\right)$ 两个 部分。 $g_{\text {ias }}$ 代表 $\mathrm{CO}_{2}$ 从气孔下腔到细胞壁周围扩散阻 力的倒数, $g_{\mathrm{liq}}$ 代表 $\mathrm{CO}_{2}$ 从细胞壁周围到叶绿体内羧 化位点扩散阻力的倒数。

$$
g_{\mathrm{m}}=\frac{1}{\frac{1}{g_{\text {ias }}}+\frac{R \times T_{\mathrm{k}}}{H \times g_{\text {liq }}}}
$$

$H$ 是亨利定律常数 $\left(\mathrm{m}^{3} \cdot \mathrm{mol}^{-1} \cdot \mathrm{K}^{-1}\right), R$ 为气体常数 $\left(\mathrm{Pa} \cdot \mathrm{m}^{3} \cdot \mathrm{K}^{-1} \cdot \mathrm{mol}^{-1}\right), T_{\mathrm{k}}$ 是绝对温度 $(\mathrm{K}) 。\left(R \times T_{\mathrm{k}}\right) /(H \times$ $g_{\text {liq }}$ 是亨利定律常数的无因次形式, 可以将气相导 度转换为等价的液相导度(Niinemets \& Reichstein, 2003b)。

$$
\begin{aligned}
& g_{\text {ias }}=\frac{D_{\mathrm{a}} \times f_{\text {ias }}}{\Delta L_{\text {ias }} \times \varsigma} \\
& f_{\text {ias }}=1-\frac{\Sigma S_{\mathrm{s}}}{t_{\text {mes }} \times W}
\end{aligned}
$$

$D_{\mathrm{a}}\left(\mathrm{m}^{2} \cdot \mathrm{s}^{-1}\right)$ 是气相中 $\mathrm{CO}_{2}$ 扩散系数 $\left(25{ }^{\circ} \mathrm{C}\right.$ 下是 $\left.1.51 \times 10^{-5}\right), f_{\text {ias }}\left(\mathrm{m}^{3} \cdot \mathrm{m}^{-3}\right)$ 是细胞间隙体积与叶肉总 体积的比值。 $\Sigma S_{\mathrm{s}}$ 代表叶肉细胞横切面面积; $t_{\mathrm{mes}}$ 代表 上下表皮之间叶肉细胞的厚度; $W$ 是切片宽度; $\Delta L_{\text {ias }}$ 被近似为叶肉厚度的一半; $\zeta$ 代表扩散路径弯曲度, 用叶片横切面和纵切面进行估算(Terashima et al., 1995), 一般用常数 $1.57 \mathrm{~mm}^{-1}$ (Syvertsen et al., 1995; Niinemets \& Reichstein, 2003a)。

$$
g_{\text {liq }}=\frac{S_{\mathrm{m}}}{\left(1 / g_{\mathrm{cw}}+1 / g_{\mathrm{pl}}+1 / g_{\text {cel, tot }}\right) \times S}
$$

$S_{\mathrm{m}} / S$ 代表单位叶片面积内面向细胞间隙的叶肉细胞 面积; $g_{\mathrm{cw}}$ 是细胞壁导度, $g_{\mathrm{p} 1}$ 是质膜导度, $g_{\mathrm{cel}, \mathrm{tot}}$ 是细胞 


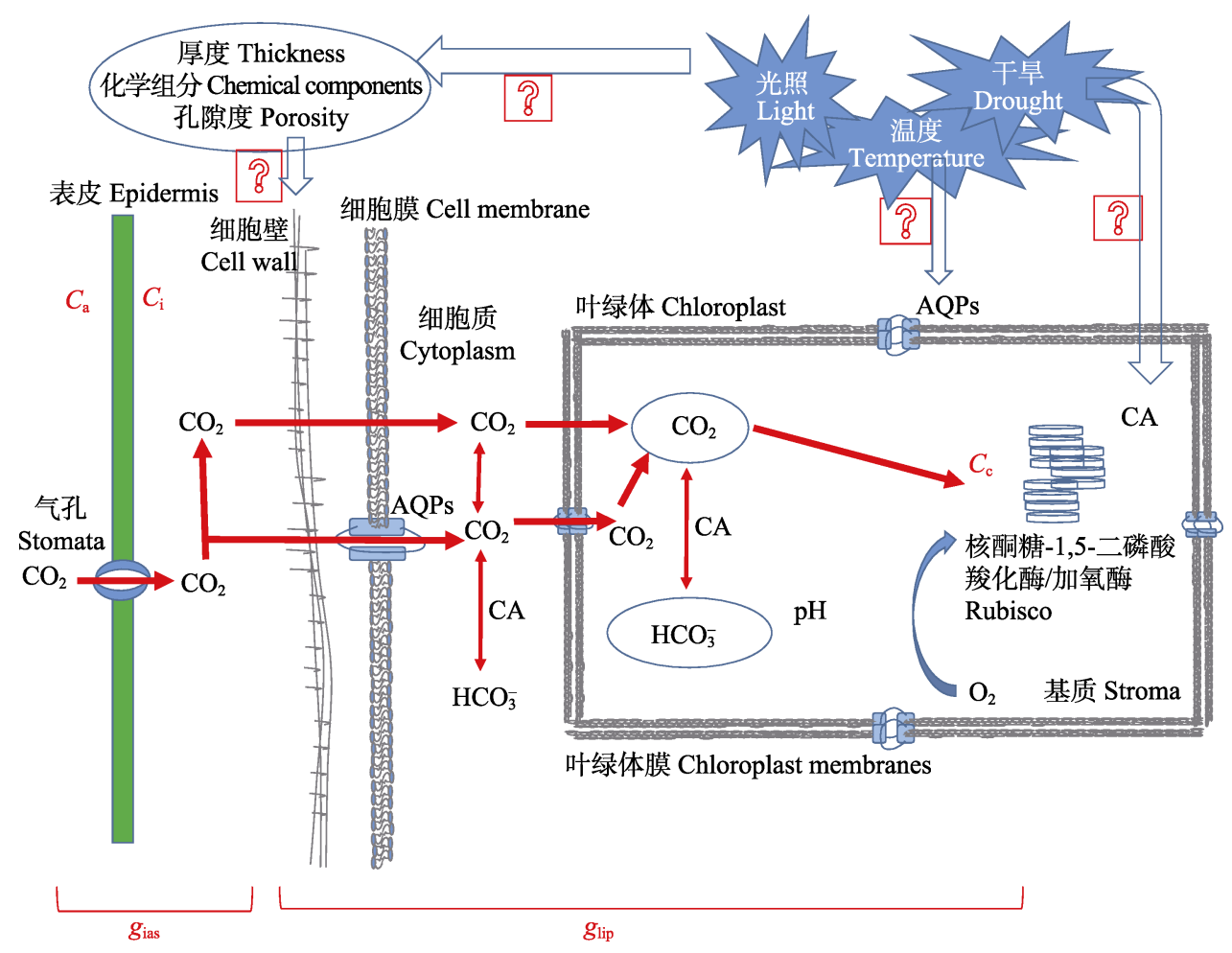

图1 $\mathrm{CO}_{2}$ 运输模式图。 $\mathrm{AQPs}$, 水孔蛋白; $C_{\mathrm{a}}$, 大气 $\mathrm{CO}_{2}$ 浓度; $C_{\mathrm{i}}$, 胞间 $\mathrm{CO}_{2}$ 浓度; $\mathrm{CA}$, 碳酸酐酶; $g_{\text {ias }}$, 气相导度; $g_{\mathrm{lip}}$, 液相导度。 Fig. $1 \mathrm{CO}_{2}$ transport model. AQPs, aquaporins; $C_{\mathrm{a}}$, the atmospheric $\mathrm{CO}_{2}$ concentration; $C_{\mathrm{i}}$, intercellular $\mathrm{CO}_{2}$ concentration; $\mathrm{CA}$, carbonic anhydrase; $g_{\text {ias }}$, the gas phase conductance; $g_{\text {lip }}$, the liquid phase conductance.

A

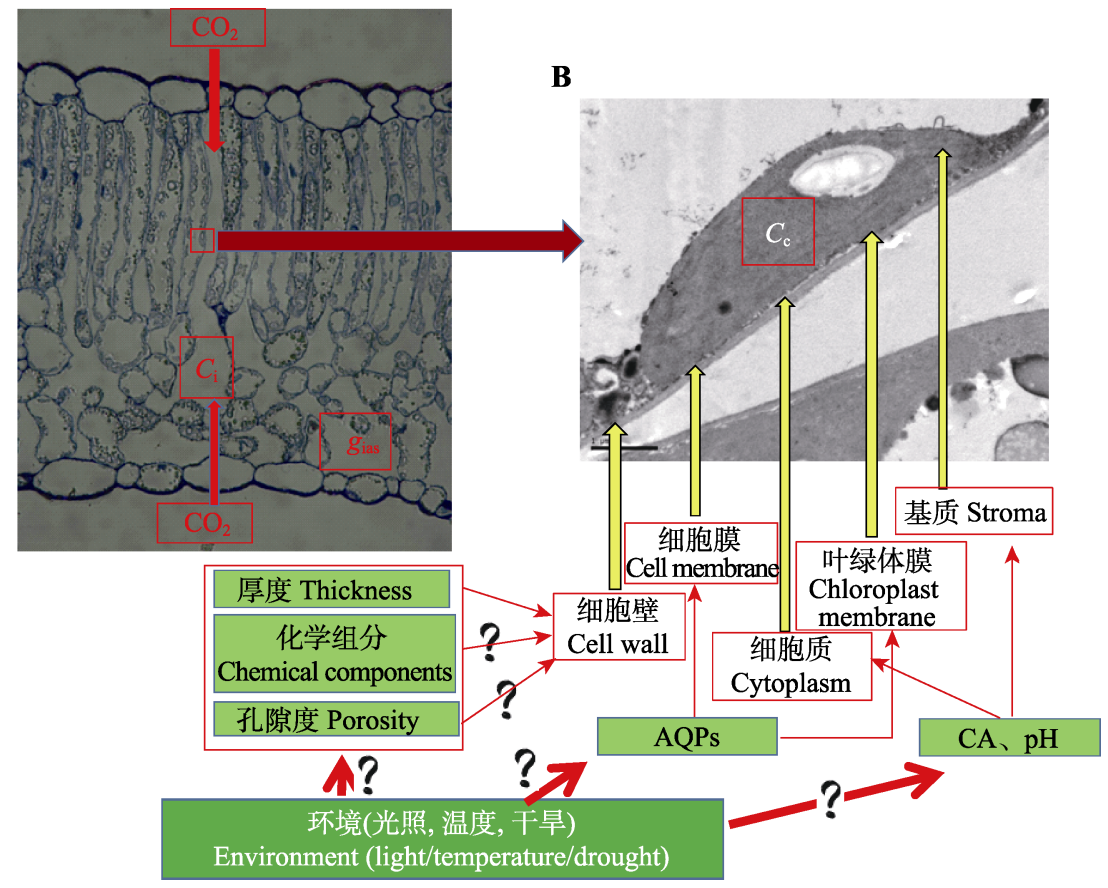

图2 $g_{\mathrm{m}}$ 反映的 $\mathrm{CO}_{2}$ 扩散路径。 $\mathrm{A}$, 光学显微镜拍摄的棉花叶片解剖结构图, 代表的是 $\mathrm{CO}_{2}$ 从外界大气进入叶片细胞间隙, 完成 气相传输。 $\mathbf{B}$, 电子显微镜拍摄的棉花叶片超微结构图。代表的是 $\mathrm{CO}_{2}$ 从细胞间隙进入叶绿体羧化位点所经过的部位, 完成液 相传输。图中简单介绍了影响传输路径的因素及需要进一步深入研究的问题。AQPs, 水孔蛋白; $C_{\mathrm{i}}$, 胞间 $\mathrm{CO}_{2}$ 浓度; $C_{\mathrm{c}}$, 叶绿 体羧化位点 $\mathrm{CO}_{2}$ 浓度; $\mathrm{CA}$, 碳酸酐酶, $g_{\text {ias }}$, 液相导度。

Fig. 2 The diffusion path of $\mathrm{CO}_{2}$ reflected by $g_{\mathrm{m}}$. A, The leaf anatomical structure in cotton by optical microscope, which represents the $\mathrm{CO}_{2}$ gas phase diffusion from the atmosphere into the leaf intercellular air layer; $\mathbf{B}$, The leaf ultra-micro structure in cotton by electron microscope, which represents the $\mathrm{CO}_{2}$ liquid phase diffusion from intercellular into the chloroplast carboxylation site. AQPs, aquaporins; $C_{\mathrm{i}}$, intercellular $\mathrm{CO}_{2}$ concentration; $C_{\mathrm{c}}, \mathrm{CO}_{2}$ concentration at chloroplast carboxylation site; $\mathrm{CA}$, carbonic anhydrase; $g_{\text {ias }}$, the gas phase conductance.

www.plant-ecology.com 
内部导度。三者通用的表达方式 $g_{\mathrm{i}}$ 计算公式为:

$$
g_{\mathrm{i}}=\frac{r_{\mathrm{f}, \mathrm{i}} \times D_{\mathrm{w}} \times p_{\mathrm{i}}}{\Delta L_{\mathrm{i}}}
$$

$P_{\mathrm{i}}$ 是扩散路径有效孔隙度, 对于胞液和基质用常数 1, 细胞壁的孔隙度用常数 0.05 (Terashima et al., 2006), $D_{\mathrm{w}}$ 是 $\mathrm{CO}_{2}$ 液相扩散系数 $\left(1.790 \times 10^{-9} \mathrm{~m}^{2} \cdot \mathrm{s}^{-1}\right.$, $\left.25{ }^{\circ} \mathrm{C}\right), r_{\mathrm{f}, \mathrm{i}}$ 是无量纲因子, 用来表示与 $\mathrm{CO}_{2}$ 在水中的 自由扩散相比, 液相扩散导度的下降。针对 $g_{\mathrm{cw}}, r_{\mathrm{f} . \mathrm{i}}$ 用常数 $1 ; \Delta L_{\mathrm{i}}$ 是指扩散路径长度。其中计算 $g_{\text {cel,tot }}$ 时, 扩散路径较为复杂, 一般将 $\mathrm{CO}_{2}$ 从细胞膜下进入到 叶绿体分为两个路径: 一是 $\mathrm{CO}_{2}$ 从细胞质沿垂直细 胞膜的方向进入叶绿体; 二是细胞质中的 $\mathrm{CO}_{2}$ 可沿 平行细胞膜的方向进入叶绿体侧面(Terashima et al., 2005; Tomás et al., 2013)。 $g_{\mathrm{p} 1}$ 和 $g_{\mathrm{en}}$ (叶绿体膜导度) 不适用于此公式, 一般用常数 $0.0035 \mathrm{~m} \cdot \mathrm{s}^{-1}$ (Evans et al., 1994)表示。

由以上公式可知, 气相扩散路径弯曲度、细胞 壁扩散路径有效孔隙度、液相扩散系数等均采用常 数。除此之外, 扩散路径的长度, 如细胞壁厚度、叶 绿体大小和位置等均对 $g_{\mathrm{m}}$ 的计算有重要影响。尽管 气相扩散涉及垂直扩散路径和侧向扩散路径, 但有 研究报道气相扩散相对于液相扩散可以忽略不计。 同时, 结构量化时假设生物膜限制为常数, 实际上 生物膜的限制也是影响 $g_{\mathrm{m}}$ 的不可忽视的因素。

Tomás等(2014)认为影响 $g_{\mathrm{m}}$ 的主要因素随物种特性 的变化而变化, 例如在肉质植株中影响 $g_{\mathrm{m}}$ 最重要的 因素是生物膜通透性、细胞液和叶绿体基质等生化 层面的因素; 而在硬叶植株中细胞壁厚度是限制 $g_{\mathrm{m}}$ 的主要因素。

\subsection{1 细胞壁}

影响 $g_{\mathrm{m}}$ 的细胞壁特性主要为厚度和孔隙度。一 般认为细胞壁的厚度与 $g_{\mathrm{m}}$ 呈反比, 扩散路径越大, 厚度越厚, $g_{\mathrm{m}}$ 越小。研究证实, 细胞壁的厚度与 $g_{\mathrm{m}}$ 确实存在负相关关系(Terashima et al., 2011)。在硬 叶植物中 $g_{\mathrm{m}}$ 的限制主要来自于细胞壁厚度的限制 (Evans et al., 2009)。同时, 细胞壁越厚的叶片, 单位 $S_{\mathrm{c}}$ 下的Rubisco含量越少, 叶绿体越小, 光合速率也 就越低(Evans et al., 2009)。Tosens等(2012b)认为不 仅细胞壁厚度影响着 $g_{\mathrm{m}}$, 细胞孔隙度也与 $g_{\mathrm{m}}$ 关系密 切。一般认为细胞壁孔隙度越大, $g_{m}$ 越大。研究证 实, 物种间细胞壁孔隙度随细胞壁厚度的变化而变 化(Terashima et al., 2006; Evans et al., 2009; Tosens et al., 2012b)。Tosens等(2012b)利用最小二乘迭代分 析法对细胞壁孔隙度进行分析, 结果显示, 细胞壁 厚度由 $0.252 \mu \mathrm{m}$ 到 $0.420 \mu \mathrm{m}$ 变化的物种, 相对应的 细胞孔隙度由 0.095 变化到 0.040 。细胞壁的主要成 分包括纤维素和半纤维素, 研究细胞壁物理结构和 化学组分的相互作用对于理解 $g_{\mathrm{m}}$ 的变化机制至关 重要(Flexas \& Diaz-Espejo, 2015)。然而, 两者如何 受外界因素的影响以及如何相互作用来影响 $\mathrm{CO}_{2}$ 的 传输尚未有细致的研究报道。

\subsection{2 生物膜}

生物膜对脂溶性小分子具有透过性, $\mathrm{CO}_{2}$ 是亲 脂性分子, 能够经过磷脂双分子层进行快速穿膜扩 散。早先一直认为 $\mathrm{CO}_{2}$ 在生物膜上的扩散速率非常 大, 磷脂双分子层对 $\mathrm{CO}_{2}$ 的阻碍(脂相阻碍)可以忽 略不计。然而对水孔蛋白(AQPs)的研究表明, 它不 仅介导 $\mathrm{H}_{2} \mathrm{O}$ 的跨膜运输, 对 $\mathrm{CO}_{2}$ 的跨膜运输也起着 重要作用。Terashima等(2006)认为 $\mathrm{CO}_{2}$ 的穿膜过程 主要通过两种途径: 磷脂双分子层和膜上内在蛋 白。然而, 不同研究对 $\mathrm{CO}_{2}$ 在生物膜上的通透系数的 估测值相差甚大。Missner等(2008)估测膜的通透性 是 $(3.2 \pm 1.6) \mathrm{cm} \cdot \mathrm{s}^{-1}$, 认为影响 $\mathrm{CO}_{2}$ 跨膜运输的主要 因素是生物膜边界层厚度, 与 $\mathrm{AQPs}$ 关系不大; 而 Boron等(2011)在排除AQPs的功能后估测细胞膜通 透性为 $0.015 \mathrm{~cm} \cdot \mathrm{s}^{-1}$, 从而认为, $\mathrm{AQPs}$ 通过影响 $\mathrm{CO}_{2}$ 在生物膜上的运输来调控 $g_{\mathrm{m}}$ 。 Uehlein等(2008)证实 AQPs基因的沉默降低了叶绿体内 $\mathrm{CO}_{2}$ 的浓度; 而当 超表达AQPs时, $g_{\mathrm{m}}$ 得到了改善, 从而提高了光合速 率(Sade et al., 2014)。另外, AQPs也可以通过影响 $g_{\mathrm{s}}$ 从而影响光合作用(Hanba et al., 2004; Flexas et al., 2006b; Heckwolf et al., 2011)。

\subsection{3 基质}

$\mathrm{CO}_{2}$ 从细胞膜扩散到叶绿体膜需要经过细胞质, $\mathrm{CO}_{2}$ 在细胞质中的扩散路径越长, $\mathrm{CO}_{2}$ 所受到的阻碍 越大。通常, 叶绿体会沿细胞膜排列(Sage \& Sage, 2009), 这有助于缩短 $\mathrm{CO}_{2}$ 在细胞质中的扩散路径, 从而减少扩散阻碍。同时, $\mathrm{CO}_{2}$ 进入到叶绿体后还会 受到叶绿体基质的阻力, 叶绿体越大, $\mathrm{CO}_{2}$ 从叶绿体 基质扩散到羧化位点的路径越短, 阻力越小, $g_{\mathrm{m}}$ 越 大。面向细胞间隙的叶绿体面积 $\left(S_{\mathrm{c}}\right)$ 是接受 $\mathrm{CO}_{2}$ 的主 要部位, 但部分 $\mathrm{CO}_{2}$ 也会通过叶绿体之间的空隙进 入到细胞质, 之后在叶绿体侧面扩散进入叶绿体, 但此扩散路径长于垂直进入叶绿体的扩散路径, 不 
利于 $\mathrm{CO}_{2}$ 的快速扩散和光合速率的改善。

综上所述, 尽管大量证据表明解剖结构对 $g_{\mathrm{m}}$ 的 影响极其重要, 但各部分结构因素(例如细胞壁)影 响 $g_{\mathrm{m}}$ 的机理并不清楚, 仍需要进一步深入的探讨。

\section{2 生化层面的限制}

\subsection{1 碳酸酐酶}

$\mathrm{CA}$ 可以通过催化 $\mathrm{CO}_{2}$ 和 $\mathrm{HCO}_{3}^{-}$之间的可逆转换 来调节细胞中的 $\mathrm{pH}$ 变化, 促进 $\mathrm{CO}_{2}$ 的传输。近年来, 关于 $\mathrm{CA}$ 对 $g_{\mathrm{m}}$ 产生影响的报道较多, 但结论迥异。

Price等(1994)和Williams等(1996)研究发现在CA活 性非常低的突变体植株中, 植株光合能力的差异并 不大, 认为CA对光合作用无限制作用。但也有作者 认为 $\mathrm{CA}$ 的活性具有物种依赖性, 如硬叶植株中 CA 往往能发挥很大的作用(Gillon \& Yakir, 2000)。

Jia和Davies (2007)报道非原质体内 $\mathrm{pH}$ 值为5.56.0 , 可能 $\mathrm{CA}$ 不会影响 $\mathrm{CO}_{2}$ 从细胞壁到细胞膜的传 输; 细胞膜和叶绿体膜仅对 $\mathrm{CO}_{2}$ 有通透性作用, 对 $\mathrm{HCO}_{3}^{-}$具有不透过性; 同时, 细胞质中的 $\mathrm{pH}$ 值小于 叶绿体基质中的pH值, Evans等(2009)认为CA不会 催化细胞质中 $\mathrm{CO}_{2}$ 和 $\mathrm{HCO}_{3}^{-}$的可逆转化。因此, $\mathrm{CA}$ 可 能并未参与 $\mathrm{CO}_{2}$ 在细胞壁、细胞膜、叶绿体膜和细 胞质中的扩散过程。研究证实, 植株中CA主要存在 于叶绿体基质中(Evans et al., 2009)。 $\mathrm{CO}_{2}$ 不断穿膜 进入叶绿体羧化位点, 随着羒化速率的进行, 叶绿 体基质内的 $\mathrm{pH}$ 值逐渐升高, $\mathrm{HCO}_{3}^{-}$也逐渐增多, 从而 与细胞质中形成了 $\mathrm{CO}_{2}$ 浓度差, 加速了 $\mathrm{CO}_{2}$ 的跨膜 扩散; 在此过程中 $\mathrm{CA}$ 通过催化 $\mathrm{CO}_{2}$ 和 $\mathrm{HCO}_{3}^{-}$的可逆 反应来调节叶绿体内的 $\mathrm{pH}$ 值, 同时加速 $\mathrm{CO}_{2}$ 向叶绿 体羧化酶活性部位的扩散, 维持羧化酶周围 $\mathrm{CO}_{2}$ 的 浓度以保证其不会随同化过程的进行而降低, 从而 保持一定的光合速率(Tholen \& Zhu, 2011)。也许这 可以证明 $\mathrm{CA}$ 通过加强叶绿体内 $\mathrm{CO}_{2}$ 的扩散来影响 $g_{\mathrm{m}}$ 。然而, 正常生理 $\mathrm{pH}$ 值下, $\mathrm{HCO}_{3}^{-}$的浓度是 $\mathrm{CO}_{2}$ 浓 度的85倍左右, $\mathrm{HCO}_{3}^{-}$决定了细胞内无机碳的扩散速 率, 但羧化酶的底物是 $\mathrm{CO}_{2}$ 而不是 $\mathrm{HCO}_{3}^{-}$。这暗示 $\mathrm{CO}_{2}$ 的扩散量不足以满足 $\mathrm{CO}_{2}$ 固定的需求(Evans et al., 2009)。Tholen和Zhu (2011)通过建立的三维模型 估算 $\mathrm{CA}$ 的量, 认为基质中的 $\mathrm{CA}$ 并不够多, 尽管 $\mathrm{CA}$ 调节了 $\mathrm{CO}_{2}$ 和 $\mathrm{HCO}_{3}^{-}$的可逆转换, 但是在基质中还是 扮演着限制角色。研究 $\mathrm{CA}$ 催化 $\mathrm{CO}_{2}$ 和 $\mathrm{HCO}_{3}^{-}$转换的 位点和条件对于阐明 $\mathrm{CA}$ 对 $g_{\mathrm{m}}$ 的影响极其重要。

\subsection{2 水孔蛋白}

Hub和de Groot $(2006,2008)$ 基于分子模型的模 拟试验表明, $\mathrm{CO}_{2}$ 穿过水孔蛋白单体消耗的能量多 于 $\mathrm{CO}_{2}$ 直接通过磷脂双分子层的运输能量, 这似乎 并不合理。然而, 水孔蛋白家族包括大量点突变的 同系物，不同同系物对 $\mathrm{CO}_{2}$ 的通透性存在差异，可 能存在的点突变可以减少运输 $\mathrm{CO}_{2}$ 所消耗的能量 (Hub \& de Groot, 2008)。另有研究表明, 水孔蛋白四 聚物形成的孔隙介导 $\mathrm{CO}_{2}$ 和 $\mathrm{H}_{2} \mathrm{O}$ 的运输, 单体并不 会介导 $\mathrm{CO}_{2}$ 的跨膜运输(Otto et al., 2010)。四聚物形 成的孔隙运输 $\mathrm{CO}_{2}$ 消耗的能量比单体低。Flexas等 (2012)认为, 形成水孔蛋白四聚物的同系物之间存在 竞争, 以此来调节水孔蛋白运输 $\mathrm{H}_{2} \mathrm{O}$ 和 $\mathrm{CO}_{2}$ 的功能。

水孔蛋白家族根据序列同源性可以分为 5 类： 质膜内在蛋白(PIPs)、液泡膜内在蛋白(TIPs)、类 Nod26膜内在蛋白(NIPs)、小分子碱性膜内在蛋白 (SIPs) 以及类 GlpF膜内在蛋白(GIPs)(Kelly et al., 2014)。研究表明, 大部分PIPs和TIPs均属于选择性 通道蛋白，但TIPs位于液泡膜上，只有PIPs位于质 膜上, 并且既可以运输 $\mathrm{H}_{2} \mathrm{O}$, 又可以运输 $\mathrm{CO}_{2}$ 。 $\mathrm{PIPs}$ 又分为PIP1和PIP2两个亚类。Otto等(2010)认为PIP1 具有转运 $\mathrm{CO}_{2}$ 的功能, PIP2 只具有转运 $\mathrm{H}_{2} \mathrm{O}$ 的功能; 但是Hanba等(2004)的研究表明PIP2同样介导 $\mathrm{CO}_{2}$ 的 转运。AQPs是PIP1家族的成员。研究表明, 在AQPs 非特异性抑制剂 $\mathrm{HgCl}_{2}$ 处理的植株中, $g_{\mathrm{m}}$ 显著下降 (Terashima \& Ono, 2002)。而且AQPs 在细胞水平和 整株植株水平均可发挥作用, 提高植株蒸腾速率和 净光合速率(Sade et al., 2010)。Perez-Martin等(2014) 的研究表明AQPs的表达对干旱条件下油橄榄(Olea europaea) 的光合速率具有一定的影响。然而, AQPs 对 $g_{\mathrm{m}}$ 的调节机制并不清楚。因此, 研究AQPs如何调 控 $\mathrm{CO}_{2}$ 的传输过程对于理解AQPs 对 $g_{\mathrm{m}}$ 的调节机理 具有重要意义。

\section{2 外界环境对 $g_{m}$ 的影响}

研究表明, 与 $g_{\mathrm{s}}$ 相似, $g_{\mathrm{m}}$ 对外界环境(水分、温 度、光照、氮、 $\mathrm{CO}_{2}$ 浓度等)的响应也具有敏感性。

\section{1 水分亏缺对 $g_{\mathrm{m}}$ 的影响}

水分亏缺是限制植物生长和作物产量的主要 环境因素。研究表明, 水分亏缺条件下光合速率下 降的根本原因是从外界大气到叶绿体内羧化位点 $\mathrm{CO}_{2}$ 扩散速率的下降(Flexas et al., 2002; Galmés et al., 2007)。水分亏缺条件下 $g_{\mathrm{m}}$ 的降低(Flexas et al., 
2004, 2006a; Galmés et al., 2006, 2007)与 $g_{\mathrm{s}}$ 一样是限 制光合作用的主要因素。水分亏缺导致 $g_{\mathrm{m}}$ 降低的因 素主要包括结构因素(降低 $S_{\mathrm{c}}$ 增加细胞壁厚度)和生 化因素(AQPs活性的降低、CA活性的改变)。这些因 素的变化抑制了水分亏缺条件下叶片组织内部的 $\mathrm{CO}_{2}$ 传输。

\section{2 温度对 $g_{\mathrm{m}}$ 的影响}

Yamori等(2006)的研究表明, 在 30 和 $15{ }^{\circ} \mathrm{C}$ 下生 长的菠菜(Spinacia oleracea) 叶片中, $g_{\mathrm{m}}$ 达到峰值所 对应的温度分别是 25 和 $20{ }^{\circ} \mathrm{C}$; 在田间空气温度(波 动范围7-32 $\left.{ }^{\circ} \mathrm{C}\right)$ 下生长的油橄榄叶片 $g_{\mathrm{m}}$ 的最适温度 是29 ${ }^{\circ} \mathrm{C}$ (Diaz-Espejo et al., 2007); 在 $5{ }^{\circ} \mathrm{C}$ 环境下 生长的甘蓝(Brassica oleracea) 叶片, 其 $g_{\mathrm{m}}$ 峰值所对 应的温度可以达到 $18{ }^{\circ} \mathrm{C}$ (Flexas et al., 2008)。研究 表明, 纯水中 $\mathrm{CO}_{2}$ 的温度系数 $Q_{10}$ (温度每变化 10 ${ }^{\circ} \mathrm{C}, \mathrm{CO}_{2}$ 扩散速率的变化) 是 1.25 , 但在烟草中 $\mathrm{CO}_{2}$ 的 $Q_{10}$ 达到2.2 (Bernacchi et al., 2002)。以上研究表明, $g_{\mathrm{m}}$ 对温度的响应可能与酶促反应密切相关。CA和 $\mathrm{AQPs}$ 的化学性质均属于蛋白质, 两者的活性与温度 密切相关, 温度可能通过影响CA和AQPs的活性进 而对 $g_{\mathrm{m}}$ 产生影响。另外, 温度的提高也会提高蒸气 压差, 从而降低细胞的水势和膨压, 引起 $S_{\mathrm{c}}$ 的下降。

\section{3 光照强度对 $g_{\mathrm{m}}$ 的影响}

研究表明, 光照强度的改变可以调控 $g_{\mathrm{m}}$ 的大小 (Flexas et al., 2007)。阴生植物的 $g_{\mathrm{m}}$ 比阳生植物的低 (Hanba et al., 2002; Piel et al., 2002; Laisk et al., 2005; Warren et al., 2007)。Hassiotou等(2009)对Banksia的 研究发现, 低光强下发育的叶片 $g_{\mathrm{m}}$ 比高光强下平均 低 $20 \%$ 。光照强度也许通过改变叶绿体的位置来影 响 $S_{\mathrm{c}}$ 的大小, 从而改变 $g_{\mathrm{m}}$ (Tholen et al., 2008; Boex-Fontvieille et al., 2014)。大量研究还报道了短 期改变光照强度和光质对 $g_{\mathrm{m}}$ 的影响。研究发现 $g_{\mathrm{m}}$ 对 蓝光反应迅速, 而叶绿体位置不可能瞬间变化, 说 明除了光照强度对 $S_{\mathrm{c}}$ 的影响外, 也许还存在其他的 机制影响 $g_{\mathrm{m}}$ (Loreto et al., 2009)。尽管Tholen等(2012) 认为 $g_{\mathrm{m}}$ 对光强的快速响应是由于 $g_{\mathrm{m}}$ 计算过程中忽 略了叶绿体中由(光)呼吸作用产生的 $\mathrm{CO}_{2}$ 量所导致 的假象。然而, Théroux-Rancourt和Gilbert (2017)通 过多层次叶片模型和解剖观察表明, $g_{\mathrm{m}}$ 对光强存在 明显响应。因此, 光照强度影响 $g_{\mathrm{m}}$ 的具体机制还有 待深入研究。

\section{4 氮对 $g_{\mathrm{m}}$ 的影响}

植物单位叶面积的氮含量与光合能力具有显 著的正相关关系, 这主要是由于氮含量增加会提高 核酮糖-1,5-双磷酸羧化/加氧酶(Rubisco)的含量, 以 及可以增加 $\mathrm{CO}_{2}$ 扩散导度 (包括 $g_{\mathrm{s}}$ 和 $g_{\mathrm{m}}$ ) (Warren, 2004; Li et al., 2009; Yamori et al., 2011)。研究认为, 氮可以通过改变叶片结构来调控 $g_{\mathrm{m}}$ 的大小。高氮条 件下Rubisco含量的增加势必会造成叶绿体体积的 增大(Li et al., 2009), 从而导致 $S_{\mathrm{c}}$ 的增加, 并最终影 响 $g_{\mathrm{m}}$ 。Xiong等(2015b)对水稻(Oryza sativa)的研究也 表明 $S_{\mathrm{c}}$ 对氮营养的响应较敏感。氮含量也可能通过 调控叶片相关的基因表达来影响 $g_{\mathrm{m}}$ 的大小。 Clarkson等(2000)认为氮含量的提高会增加PIP2水 孔蛋白基因家族的表达量; Hanba等 (2004)认为 PIP2; 1 水孔蛋白的超表达可以提高 $g_{\mathrm{m}}$ 。然而, 直至目 前, 尚未发现氮含量通过调控AQPs改变 $g_{\mathrm{m}}$ 的直接 证据。另外, 虽然有研究发现水稻、小麦(Triticum aestivum)、菠菜等 $\mathrm{C}_{3}$ 植物(Makino et al., 1992)和玉米 (Zea mays) 等 $\mathrm{C}_{4}$ 植物(Burnell et al., 1990)的CA活性 均会受到氮的影响, 但CA对 $g_{\mathrm{m}}$ 的调控还一直存在 争议。因此, 基因表达活性蛋白对氮的响应从而对 $g_{\mathrm{m}}$ 的调控机理尚需进一步研究。

\section{$3 g_{\mathrm{m}}$ 的估算方法}

目前, 估算 $g_{\mathrm{m}}$ 最常用的 3 种方法包括气体交换 和叶绿素荧光同步测定法(Bongi \& Loreto, 1989; Harley et al., 1992; Loreto et al., 1992)、气体交换和 同位素同步测定法(Evans et al., 1986; von Caemmerer \& Evans, 1991)和 $A_{\mathrm{N}} C_{\mathrm{i}}$ 曲线拟合法(Ethier \& Livingston, 2004; Sharkey et al., 2007)。研究表明 $g_{\mathrm{m}}$ 的估算会受到众多因素的影响，例如细胞间隙 $\mathrm{CO}_{2}$ 浓度 $\left(C_{\mathrm{i}}\right)$ (Flexas et al., 2007)、光照强度(Flexas et al., 2007; Tholen et al., 2008)等因素。尽管大量研究者致 力于 $g_{\mathrm{m}}$ 估算方法的研究与改善, 但现有方法均无法 准确估算出 $g_{\mathrm{m}}$ 的绝对数值 (Flexas et al., 2008; Warren, 2008)。如Tholen等(2012)认为 $g_{\mathrm{m}}$ 的估算忽略 了扩散到叶绿体中由线粒体(光)呼吸作用产生的 $\mathrm{CO}_{2}$ 浓度。而且, 有研究者认为影响 $g_{\mathrm{m}}$ 的因素均是估 算方法缺陷导致的假象, 例如 Gu和Sun (2013)认为 $C_{\mathrm{i}}$ 只是 $g_{\mathrm{m}}$ 估算公式中的输入参数, $C_{\mathrm{i}}$ 及其他与之协 同变化的输入参数的测量误差均会导致 $g_{\mathrm{m}}$ 对 $C_{\mathrm{i}}$ 响应 
的假象。近几年, 受限于估算叶肉导度方法的各种 缺陷, 叶肉导度研究领域进展相对缓慢。因此, 完善 和改良 $g_{\mathrm{m}}$ 的计算和测定方法将是深入推进叶肉导 度研究的重要突破口。

\section{4 水力导度与 $g_{\mathbf{m}}$ 的关系}

$\mathrm{CO}_{2}$ 是植物进行光合作用的原料, 而 $\mathrm{H}_{2} \mathrm{O}$ 是生 物体的组成物质, 是进行一切生命活动的必需物质 和养分运输的媒介。因此, $\mathrm{CO}_{2}$ 和 $\mathrm{H}_{2} \mathrm{O}$ 在植物中的传 输关系备受关注。水力导度 $\left(K_{\text {leaf }}\right)$ 和 $g_{\mathrm{m}}$ 分别是衡量植 物叶片内 $\mathrm{H}_{2} \mathrm{O}$ 和 $\mathrm{CO}_{2}$ 运输的两个重要变量, 是决定 气体交换速率和光合性能的主要指标(Flexas et al., $2013)$ 。虽然 $K_{\text {leaf }}$ 和 $g_{\mathrm{m}}$ 一直是研究的热点, 但很少有 研究探讨两者之间的协同关系(Flexas et al., 2013)。

$K_{\text {leaf }}$ 可以反应 $\mathrm{H}_{2} \mathrm{O}$ 在叶片内传输的效率问题, $\mathrm{H}_{2} \mathrm{O}$ 从叶柄贯穿到叶片的木质部, 然后到达叶脉周 围的维管束, 最后到达蒸发位点从而扩散到空气中 (Sack \& Holbrook, 2006)。通常, $K_{\text {leaf }}$ 分为木质部导度 $\left(K_{\text {xylem }}\right)$ 和木质部外导度 $\left(K_{\text {out-xylem }}\right)$, 在叶脉内的水分 传输称为 $K_{\text {xylem, }}$, 在叶脉外组织内的传输称为 $K_{\text {out-xylem。F }}$.Flexas等(2013)研究认为, $g_{\mathrm{m}}$ 与 $K_{\text {leaf }}$ 具有相 关性, 并且主要与 $K_{\text {out-xylem }}$ 相关。 $K_{\text {out-xylem }}$ 对整个 $K_{\text {leaf }}$ 的影响较大, 但所占比例会随着物种和试验条件的 变化而变化(Cochard et al., 2004; Sack et al., 2004)。

叶片组织内 $\mathrm{H}_{2} \mathrm{O}$ 和 $\mathrm{CO}_{2}$ 有着共同的传输路径。 面向细胞间隙的叶肉细胞面积 $\left(S_{\mathrm{m}}\right)$ 被认为是同时影
响 $g_{\mathrm{m}}$ 和 $K_{\text {leaf }}$ 的因素(Xiong et al., 2016)。尽管相比于 $S_{\mathrm{m}}, S_{\mathrm{c}}$ 的变化能更好地解释 $g_{\mathrm{m}}$ 的变化 (Terashima et al., 2005, 2006; Flexas et al., 2012), 但 $S_{\mathrm{m}}$ 的大小对 $g_{\mathrm{m}}$ 的影响也是至关重要(Xiong et al., 2016)。同时, Xiong等(2015a)认为面向细胞间隙的叶肉细胞膜也 是水分由液相转变成气相从而进行蒸发的位置, 因 此 $S_{\mathrm{m}}$ 可以将两者在一定程度上联系起来。另外, 细 胞壁的厚度和孔隙度不仅是影响 $g_{\mathrm{m}}$ 的重要结构因 素，事实上也改变了木质部外水分扩散的路径，从 而影响了 $K_{\text {leafo }}$

同时，细胞壁孔隙内存在的结合水也影响着水 分的传输。事实上 $g_{\mathrm{m}}$ 与 $K_{\text {leaf }}$ 的相关性不仅取决于叶 片的组织结构, 与生化因素(AQPs)也有着一定的关 系(Flexas et al., 2012)。AQPs不仅介导 $\mathrm{H}_{2} \mathrm{O}$ 的运输, 也介导着 $\mathrm{CO}_{2}$ 的运输。Otto等(2010)和Flexas等(2012) 认为 $\mathrm{CO}_{2}$ 和 $\mathrm{H}_{2} \mathrm{O}$ 在膜上的交换运输取决于两种不同 的水孔蛋白四聚物(PIP1和PIP2)的比例。有研究证 明 $K_{\text {leaf }}$ 可以对外界环境进行响应, 如温度、光照和水 分等(Sack \& Holbrook, 2006)。 $g_{\mathrm{m}}$ 和 $K_{\text {leaf }}$ 均与结构、 生化和外部环境有一定的关联，间接表明两者间存 在一定的关系, 但尚需进一步的直接证据。

\section{5 研究展望}

$\mathrm{CO}_{2}$ 在植物叶片细胞内的传输过程极其复杂 (图1，图2；表1)。细胞水平上每个组分和环节均可 能影响 $\mathrm{CO}_{2}$ 的传输。在结构层面, 除了细胞壁厚度

表1 $\mathrm{CO}_{2}$ 通过叶肉细胞中各超微组分的扩散方式、运输形态、阻力来源、动力来源和对外界环境的响应时间等的差异

Table 1 Diffusion way, transportation form, resistance source, power source when $\mathrm{CO}_{2}$ passes through the ultrastructure components of mesophyll cells and the different response time to the external environment

\begin{tabular}{|c|c|c|c|c|c|}
\hline & $\begin{array}{l}\mathrm{CO}_{2} \text { 扩散方式 } \\
\mathrm{CO}_{2} \text { diffusion way }\end{array}$ & $\begin{array}{l}\mathrm{CO}_{2} \text { 运输形态 } \\
\mathrm{CO}_{2} \text { transportation } \\
\text { form }\end{array}$ & $\begin{array}{l}\text { 阻力来源 } \\
\text { Resistance source }\end{array}$ & $\begin{array}{l}\text { 动力来源 } \\
\text { Power source }\end{array}$ & $\begin{array}{l}\text { 对外界环境的响应时间 } \\
\text { Response time to the } \\
\text { external environment }\end{array}$ \\
\hline $\begin{array}{l}\text { 细胞壁 } \\
\text { Cell wall }\end{array}$ & $\begin{array}{l}\text { 物理和生化方式 } \\
\text { Physics and } \\
\text { biochemical mode }\end{array}$ & $\mathrm{CO}_{2}$ & $\begin{array}{l}\text { 厚度、孔隙度、果胶等组分 } \\
\text { Thickness, porosity, pectin etc. }\end{array}$ & $\begin{array}{l}\mathrm{CO}_{2} \text { 浓度差 } \\
\text { Difference of } \mathrm{CO}_{2} \text { concentration }\end{array}$ & $\begin{array}{l}\text { 最长 } \\
\text { Longest }\end{array}$ \\
\hline $\begin{array}{l}\text { 细胞膜 } \\
\text { Cell } \\
\text { membrane }\end{array}$ & $\begin{array}{l}\text { 物理和生化方式 } \\
\text { Physics and } \\
\text { biochemical mode }\end{array}$ & $\mathrm{CO}_{2}$ & $\begin{array}{l}\text { 水孔蛋白、膜两侧 } \mathrm{pH} \text { 差值 } \\
\text { AQPs, the difference of } \mathrm{pH} \text { on } \\
\text { both sides of the membrane }\end{array}$ & $\begin{array}{l}\mathrm{CO}_{2} \text { 浓度差、跨膜蛋白主动运输 } \\
\text { Difference of } \mathrm{CO}_{2} \text { concentration, } \\
\text { active transport of transmembrane } \\
\text { protein }\end{array}$ & $\begin{array}{l}\text { 较短 } \\
\text { Shorter }\end{array}$ \\
\hline $\begin{array}{l}\text { 细胞液 } \\
\text { Cytoplasm }\end{array}$ & $\begin{array}{l}\text { 生化和物理方 } \\
\text { Biochemical } \\
\text { and physical mode }\end{array}$ & $\mathrm{CO}_{2}, \mathrm{HCO}_{3}^{-}$ & $\begin{array}{l}\mathrm{CA} 、 \mathrm{pH} 、 \text { 细胞液组分 } \\
\mathrm{CA}, \mathrm{pH}, \text { cytosol component }\end{array}$ & $\begin{array}{l}\mathrm{pH}, \mathrm{CA} \text { 的催化 } \\
\mathrm{pH}, \text { catalysis of } \mathrm{CA}\end{array}$ & $\begin{array}{l}\text { 较短 } \\
\text { Shorter }\end{array}$ \\
\hline $\begin{array}{l}\text { 叶绿体膜 } \\
\text { Chloroplast } \\
\text { membranes }\end{array}$ & $\begin{array}{l}\text { 生化和物理方 } \\
\text { Biochemical } \\
\text { and physical mode }\end{array}$ & $\mathrm{CO}_{2}$ & $\begin{array}{l}\text { 水孔蛋白、膜两侧 } \mathrm{CO}_{2} \text { 浓度差 } \\
\mathrm{AQPs} \text {, the difference of } \mathrm{CO}_{2} \\
\text { concentration on both sides of } \\
\text { the membrane }\end{array}$ & $\begin{array}{l}\text { 跨膜蛋白主动运输 } \\
\text { Active transport of } \\
\text { transmembrane protein }\end{array}$ & $\begin{array}{l}\text { 较短 } \\
\text { Shorter }\end{array}$ \\
\hline $\begin{array}{l}\text { 叶绿体基质 } \\
\text { Stroma }\end{array}$ & $\begin{array}{l}\text { 生化和物理方式 } \\
\text { Biochemical } \\
\text { and physical mode) }\end{array}$ & $\mathrm{CO}_{2}, \mathrm{HCO}_{3}^{-}$ & $\mathrm{CA}, \mathrm{pH}$ & $\begin{array}{l}\mathrm{pH} 、 \mathrm{CA} \text { 的催化 } \\
\mathrm{pH} \text {, catalysis of CA }\end{array}$ & $\begin{array}{l}\text { 最短 } \\
\text { Shortest }\end{array}$ \\
\hline
\end{tabular}

CA, carbonic anhydrase; AQPs, aquaporins;

www.plant-ecology.com 
外, 开展细胞孔隙度及其化学组分对 $g_{\mathrm{m}}$ 影响机制的 研究有助于全面揭示 $g_{\mathrm{m}}$ 与结构之间的关系; 其次叶 绿体运动会改变 $S_{\mathrm{c}}$ 的大小从而影响 $g_{\mathrm{m}}$, 那么, $\mathrm{CO}_{2}$ 传 输对叶绿体位置是否具有一定的调节作用也需要进 一步开展研究。在生化层面, 尽管大量研究认为水 孔蛋白和碳酸酐酶会影响 $g_{\mathrm{m}}$ 的大小, 但水孔蛋白和 碳酸酐酶介导 $\mathrm{CO}_{2}$ 传输的规律及其机制仍需深入研 究。同时, 叶肉导度估算方法的不确定性, 严重阻碍 了对叶肉导度的深入研究。因此, 测定方法的不断 优化和改良也将是未来研究的重点。

基金项目 国家自然科学基金(U1303183和U1203283)、霍英东教育基金(141023)和国家留学基金。

\section{参考文献}

Bernacchi CJ, Portis AR, Nakano H, von Caemmerer S, Long SP (2002). Temperature response of mesophyll conductance. Implications for the determination of Rubisco enzyme kinetics and for limitations to photosynthesis in vivo. Plant Physiology, 130, 1992-1998.

Boex-Fontvieille E, Jossier M, Davanture M, Zivy M, Hodges M, Tcherkez G (2014). Differential protein phosphorylation regulates chloroplast movement in response to strong light and darkness in Arabidopsis thaliana. Plant Molecular Biology Reporter, 32, 987-1001.

Bongi G, Loreto F (1989). Gas-exchange properties of salt stressed olive (Olea europea L.) leaves. Plant Physiology, 90, 1408-1416.

Boron W, Endeward V, Gros G, Musa-Aziz R, Pohl P (2011). Intrinsic $\mathrm{CO}_{2}$ permeability of cell membranes and potential biological relevance of $\mathrm{CO}_{2}$ channels. Chemphyschem, 12, 1017-1019.

Burnell JN, Suzuki I, Sugiyama T (1990). Light induction and the effect of nitrogen status upon the activity of carbonic anhydrase in maize leaves. Plant Physiology, 94, 384-387.

Clarkson DT, Carvajal M, Henzler T, Waterhouse RN, Smyth AJ, Cooke DT, Steudle E (2000). Root hydraulic conductance: Diurnal aquaporin expression and the effects of nutrient stress. Journal of Experimental Botany, 51, 61-70.

Cochard H, Nardini A, Coll L (2004). Hydraulic architecture of leafblades: Where is the main resistance? Plant, Cell \& Environment, 27, 1257-1267.

Diaz-Espejo A, Nicolás E, Fernández JE (2007). Seasonal evolution of diffusional limitations and photosynthetic capacity in olive under drought. Plant, Cell \& Environment, 30, 922-933.

Ethier GJ, Livingston NJ (2004). On the need to incorporate sensitivity to $\mathrm{CO}_{2}$ transfer conductance into the Farquharvon Caemmerer-Berry leaf photosynthesis model. Plant,
Cell \& Environment, 27, 137-153.

Evans JR, Kaldenhoff R, Genty B, Terashima I (2009). Resistances along the $\mathrm{CO}_{2}$ diffusion pathway inside leaves. Journal of Experimental Botany, 60, 2235-2248.

Evans JR, Shatrkey TD, Berry JA, Farquhar GD (1986). Carbon isotope discrimination measured concurrently with gas exchange to investigate $\mathrm{CO}_{2}$ diffusion in leaves of higher plants. Australian Journal of Plant Physiology, 13, 281292.

Evans JR, von Caemmere S (1996). Carbon dioxide diffusion inside leaves. Plant Physiology, 110, 339-346.

Evans JR, von Caemmerer S, Setchell BA, Hudson GS (1994). The relationship between $\mathrm{CO}_{2}$ transfer conductance and leaf anatomy in transgenic tobacco with a reduced content of Rubisco. Australian Journal of Plant Physiology, 21, 475-495.

Farquhar GD, von Caemmerer S, Berry JA (1980). A biochemical model of photosynthetic $\mathrm{CO}_{2}$ assimilation in leaves of $\mathrm{C}_{3}$ species. Planta, 149, 78-90.

Flexas J, Barbour MM, Brendel O, Cabrera HM, Carriquí M, Díaz-Espejo A, Douthe C, Dreyer E, Ferrio JP, Gago J, Gallé A, Galmés J, Kodama N, Medrano H, Niinemets Ü, Peguero-Pina JJ, Pou A, Ribas-Carbó M, Tomás M, Tosens T, Warren CR (2012). Mesophyll diffusion conductance to $\mathrm{CO}_{2}$ : An unappreciated central player in photosynthesis. Plant Science, 193-194, 70-84.

Flexas J, Bota J, Cifre J, Escalona JM, Galmés J, Gulías J, Lefi EK, Martinez-Canellas SF, Moreno MT, Ribas-Carbo M (2004). Understanding down-regulation of photosynthesis under water stress: Future prospects and searching for physiological tools for irrigation management. Annal of Applied Biology, 144, 273-283.

Flexas J, Bota J, Escalona JM, Sampol B, Medrano H (2002). Effects of drought on photosynthesis in grapevines under field conditions: An evaluation of stomatal and mesophyll limitations. Functional Plant Biology, 29, 461-471.

Flexas J, Diaz-Espejo A (2015). Interspecific differences in temperature response of mesophyll conductance: Food for thought on its origin and regulation. Plant, Cell \& Environment, 38, 625-628.

Flexas J, Diaz-Espejo A, Galmés J, Kaldenhoff R, Medrano HO, Ribas-Carbó M (2007). Rapid variations of mesophyll conductance in response to changes in $\mathrm{CO}_{2}$ concentration around leaves. Plant, Cell \& Environment, 30, 1284-1298.

Flexas J, Ribas-Carbó M, Bota J, Galmés J, Henkle M, Martínez-Cañellas S, Medrano H (2006a). Decreased Rubisco activity during water stress is not induced by decreased relative water content but related to conditions of low stomatal conductance and chloroplast $\mathrm{CO}_{2}$ concentration. New Phytologist, 172, 73-82.

Flexas J, Ribas-Carbó M, Diaz-Espejo A, Galmés J, Medrano H (2008). Mesophyll conductance to $\mathrm{CO}_{2}$ : Current knowledge 
and future prospects. Plant, Cell \& Environment, 31, 602-621.

Flexas J, Ribas-Carbó M, Hanson DT, Bota J, Otto B, Cifre J, McDowell N, Medrano H, Kaldenhoff R (2006b). Tobacco aquaporin NtAQP1 is involved in mesophyll conductance to $\mathrm{CO}_{2}$ in vivo. The Plant Journal, 48, 427-439.

Flexas J, Scoffoni C, Gago J, Sack L (2013). Leaf mesophyll conductance and leaf hydraulic conductance: An introduction to their measurement and coordination. Journal of Experimental Botany, 64, 3965-3981.

Galmés J, Medrano H, Flexas J (2006). Acclimation of Rubisco specificity factor to drought in tobacco: Discrepancies between in vitro and in vivo estimations. Journal of Experimental Botany, 57, 3659-3667.

Galmés J, Medrano H, Flexas J (2007). Photosynthetic limitations in response to water stress and recovery in Mediterranean plants with different growth forms. New Phytologist, 175, 81-93.

Gillon JS, Yakir D (2000). Internal conductance to $\mathrm{CO}_{2}$ diffusion and $\mathrm{C}^{18} \mathrm{OO}$ discrimination in $\mathrm{C}_{3}$ leaves. Plant Physiology, 123, 201-213.

Gu L, Sun Y (2013). Artefactual responses of mesophyll conductance to $\mathrm{CO}_{2}$ and irradiance estimated with the variable $\mathrm{J}$ and online isotope discrimination methods. Plant, Cell \& Environment, 37, 1231-1249.

Han JM, Meng HF, Wang SY, Jiang CD, Liu F, Zhang WF, Zhang YL (2016). Variability of mesophyll conductance and its relationship with water use efficiency in cotton leaves under drought pretreatment. Journal of Plant Physiology, 194, 61-71.

Hanba YT, Kogami H, Terashima I (2002). The effect of growth irradiance on leaf anatomy and photosynthesis in Acer species differing in light demand. Plant, Cell \& Environment, 25, 1021-1030.

Hanba YT, Miyazawa SI, Terashima I (1999). The influence of leaf thickness on the $\mathrm{CO}_{2}$ transfer conductance and leaf stable carbon isotope ratio for some evergreen tree species in Japanese warm temperate forests. Functional Ecology, 13, 632-639.

Hanba YT, Shibasaka M, Hayashi Y, Hayakawa T, Kasamo K, Terashima I, Katsuhara M (2004). Overexpression of the barley aquaporin HvPIP2; 1 increases internal $\mathrm{CO}_{2}$ conductance and $\mathrm{CO}_{2}$ assimilation in the leaves of transgenic rice plants. Plant Cell Physiology, 45, 521-529.

Harley PC, Loreto F, Marco GD, Sharkey TD (1992). Theoretical considerations when estimating the mesophyll conductance to $\mathrm{CO}_{2}$ flux by analysis of the response of photosynthesis to $\mathrm{CO}_{2}$. Plant Physiology, 98, 1429-1436.

Hassiotou F, Ludwig M, Renton M, Veneklaas EJ, Evans JR (2009). Influence of leaf dry mass per area, $\mathrm{CO}_{2}$, and irradiance on mesophyll conductance in sclerophylls. Journal of Experimental Botany, 60, 2303-2314.
Heckwolf M, Pater D, Hanson DT, Kaldenhoff R (2011). The Arabidopsis thaliana aquaporin AtPIP1;2 is a physiologically relevant $\mathrm{CO}_{2}$ transport facilitator. Plant Journal, $67,795-804$.

Hub JS, de Groot BL (2006). Does $\mathrm{CO}_{2}$ permeate through aquaporin-1? Biophysical Journal, 91, 842-848.

Hub JS, de Groot BL (2008). Mechanism of selectivity in aquaporins and aquaglyceroporins. Proceedings of the $\mathrm{Na}$ tional Academy of Sciences of the United States of America, 105, 1198-1203.

Jia WS, Davies WJ (2007). Modification of leaf apoplastic pH in relation to stomatal sensitivity to root-sourced abscisic acid signals. Plant Physiology, 143, 68-77.

Kelly G, Sade N, Attia Z, Secchi F, Zwieniecki M, Holbrook NM, Levi A, Alchanatis V, Moshelion M, Granot D (2014). Relationship between hexokinase and the aquaporin PIP1 in the regulation of photosynthesis and plant growth. PLOS ONE, 9, e87888. doi:10.1371/journal.pone. 0087888.

Laisk A, Eichelmann H, Oja V, Rasulov B, Padu E, Bichele I, Pettai H, Kull O (2005). Adjustment of leaf photosynthesis to shade in a natural canopy: Rate parameters. Plant, Cell \& Environment, 28, 375-388.

Li Y, Gao YX, Xu XM, Shen QR, Guo SW (2009). Lightsaturated photosynthetic rate in high-nitrogen rice (Oryza sativa L.) leaves is related to chloroplastic $\mathrm{CO}_{2}$ concentration. Journal of Experimental Botany, 60, 2351-2360.

Loreto F, Harley PC, Di Marco G, Sharkey TD (1992). Estimation of mesophyll conductance to $\mathrm{CO}_{2}$ flux by three different methods. Plant Physiology, 98, 1437-1443.

Loreto F, Tsonev T, Centritto M (2009). The impact of blue light on leaf mesophyll conductance. Journal of Experimental Botany, 60, 2283-2290.

Makino A, Sakashita H, Hidema J, Mae T, Ojima K, Osmond B (1992). Distinctive responses of ribulose-1,5-bisphosphate carboxylase and carbonic anhydrase in wheat leaves to nitrogen nutrition and their possible relationships to $\mathrm{CO}_{2}$-transfer resistance. Plant Physiology, 100, $1737-$ 1743.

Missner A, Kugler P, Antonenko YN, Pohl P (2008). Passive transport across bilayer lipid membranes: Overton continues to rule. Proceedings of the National Academy of Sciences of the United States of America, 1778, 2154-2156.

Miyazawa SI, Yoshimura S, Shinzaki Y, Maeshima M, Miyake $\mathrm{C}$ (2008). Relationship between mesophyll $\mathrm{CO}_{2}$ gas diffusion conductance and leaf plasma-membrane-type aquaporin contents in tobacco plants grown under drought conditions. Photosynthesis, 91, 805-808.

Moualeu-Ngangue DP, Chen T-W, Stutzel H (2016). A new method to estimate photosynthetic parameters through net assimilation reteintercellular space $\mathrm{CO}_{2}$ concentration $\left(A-C_{\mathrm{i}}\right)$ curve and chlorophyll fluorescence measurements.

www.plant-ecology.com 
New Phytologist, 213, 1543-1554.

Niinemets Ü, Reichstein M (2003a). Controls on the emission of plant volatiles through stomata: A sensitivity analysis. Journal of Geophysical Research, 108, 4211. doi: 4210.1029/2002JD002626.

Niinemets Ü, Reichstein M (2003b). Controls on the emission of plant volatiles through stomata: Sensitivity or insensitivity of the emission rates to stomatal closure explained. Journal of Geophysical Research, 108, 4208. doi: 4210.1029/2002JD002620.

Niinemets Ü, Diaz-Espejo A, Flexas J, Galmés J, Warren CR (2009). Importance of mesophyll diffusion conductance in estimation of plant photosynthesis in the field. Journal of Experimental Botany, 60, 2271-2282.

Otto B, Uehlein N, Sdorra S, Fischer M, Ayaz M, BelasteguiMacadam X, Heckwolf M, Lachnit M, Pede N, Priem N (2010). Aquaporin tetramer composition modifies the function of tobacco aquaporins. Journal of Biological Chemistry, 285, 31253-31260.

Pakatas A, Stavrakas D, Fisarakis I (2003). Relationship between $\mathrm{CO}_{2}$ assimilation and leafanatomical characteristics of two grapevine cultivars. Agronomie, 23, 293-296.

Perez-Martin A, Michelazzo C, Torres-Ruiz JM, Flexas J, Fernández JE, Sebastiani L, Diaz-Espejo A (2014). Regulation of photosynthesis and stomatal and mesophyll conductance under water stress and recovery in olive trees: Correlation with gene expression of carbonic anhydrase and aquaporins. Journal of Experimental Botany, 65, 3143-3156.

Piel C, Frak E, Le Roux X, Genty B (2002). Effect of local irradiance on $\mathrm{CO}_{2}$ transfer conductance of mesophyll in walnut. Journal of Experimental Botany, 53, 2423-2430.

Price DG, von Caemmerer S, Evans JR, Yu JW, Lloyd J, Oja V, Kell P, Harrison K, Gallagher A, Badger M (1994). Specific reduction of chloroplast carbonic anhydrase activity by antisense RNA in transgenic tobacco plants has a minor effect on photosynthetic $\mathrm{CO}_{2}$ assimilation. Planta, 193, 331-340.

Sack L, Holbrook NM (2006). Leaf hydraulics. Annual Review of Plant Biology, 57, 361-381.

Sack L, Streeter CM, Holbrook NM (2004). Hydraulic analysis of water flow through leaves of sugar maple and red oak. Plant Physiology, 134, 1824-1833.

Sade N, Gallé A, Flexas J, Lerner S, Peleg G, Yaaran A, Moshelion M (2014). Differential tissue-specific expression of NtAQP1 in Arabidopsis thaliana reveals a role for this protein in stomatal and mesophyll conductance of $\mathrm{CO}_{2}$ under standard and salt-stress conditions. Planta, 239, 357-366.

Sade N, Gebretsadik M, Seligmann R, Schwartz A, Wallach R, Moshelion M (2010). The Role of tobacco aquaporin 1 in improving water use efficiency, hydraulic conductivity, and yield production under salt stress. Plant Physiology, $152,245-254$.

Sage TL, Sage RF (2009). The functional anatomy of rice leaves: Implications for refixation of photorespiratory $\mathrm{CO}_{2}$ and efforts to engineer $\mathrm{C}_{4}$ photosynthesis into rice. Plant Cell Physiology, 50, 756-772.

Sharkey TD, Bernacchi CJ, Farquhar GD, Singsaas EL (2007). Fitting photosynthetic carbon dioxide response curves for $\mathrm{C}_{3}$ leaves. Plant, Cell \& Environment, 30, 1035-1040.

Syvertsen JP, Lloyd J, Meconchie C, Kriedbmann PE, Farquhar GD (1995). On the relationship between leaf anatomy and $\mathrm{CO}_{2}$ diffusion through the mesophyll of hypostomatous leaves. Plant Cell Physiology, 18, 149-157.

Terashima I, Araya T, Miyazawa S-I, Sone K, Yano S (2005). Construction and maintenance of the optimal photosynthetic systems of the leaf, herbaceous plant and tree: An eco-developmental treatise. Annals of Botany, 95, 507519.

Terashima I, Hanba YT, Tazoe Y, Vyas P, Yano S (2006). Irradiance and phenotype: Comparative eco-development of sun and shade leaves in relation to photosynthetic $\mathrm{CO}_{2}$ diffusion. Journal of Experimental Botany, 57, 343-354.

Terashima I, Hanba YT, Tholen D, Niinemets U (2011). Leaf functional anatomy in relation to photosynthesis. Plant Physiology, 155, 108-116.

Terashima I, Hikosaka K (1995). Comparative ecophysiology/ anatomy of leaf and canopy photosynthesis. Plant, Cell \& Environment, 18, 1111-1128.

Terashima I, Ono K (2002). Effects of $\mathrm{HgCl}_{2}$ on $\mathrm{CO}_{2}$ dependence of leaf photosynthesis: Evidence indicating involvement of aquaporins in $\mathrm{CO}_{2}$ diffusion across the plasma membrane. Plant Cell Physiology, 43, 70-78.

Théroux-Rancourt G, Gilbert ME (2017). The light response of mesophyll conductance is controlled by structure across leaf profiles. Plant, Cell \& Environment, 40, 726-740.

Tholen D, Boom C, Noguchi K, Ueda S, Katase T, Terashima I (2008). The chloroplast avoidance response decreases internal conductance to $\mathrm{CO}_{2}$ diffusion in Arabidopsis thaliana leaves. Plant, Cell \& Environment, 31, 1688-1700.

Tholen D, Ethier G, Genty B, Pepin S, Zhu XG (2012). Variable mesophyll conductance revisited: Theoretical background and experimental implications. Plant, Cell \& Environment, 35, 2087-2103.

Tholen D, Zhu XG (2011). The mechanistic basis of internal conductance: A theoretical analysis of mesophyll cell photosynthesis and $\mathrm{CO}_{2}$ diffusion. Plant Physiology, 156, 90-105.

Tomás M, Flexas J, Copolovici L, Galmes J, Hallik L, Medrano H, Ribas-Carbó M, Tosens T, Vislap V, Niinemets Ü (2013). Importance of leaf anatomy in determining mesophyll diffusion conductance to $\mathrm{CO}_{2}$ across species: Quantitative limitations and scaling up by models. Journal of Experimental 
Botany, 64, 2269-2281.

Tomás M, Medrano H, Brugnoli E, Escalona JM, Martorell S, Pou A, Ribas-Carbó M, Flexas J (2014). Variability of mesophyll conductance in grapevine cultivars under water stress conditions in relation to leaf anatomy and water use efficiency. Australian Journal of Grape and Wine Research, 20, 272-280.

Tosens T, Niinemets Ü, Vislap V, Eichelmann H, Castro Diez P (2012a). Developmental changes in mesophyll diffusion conductance and photosynthetic capacity under different light and water availabilities in Populus tremula: How structure constrains function. Plant, Cell \& Environment, $35,839-856$.

Tosens T, Niinemets Ü, Westoby M, Wright IJ (2012b). Anatomicalbasis of variation in mesophyll resistance in eastern Australian sclerophylls: News of a long and winding path. Journal of Experimental Botany, 63, 5105-5119.

Uehlein N, Otto B, Hanson DT, Fischer M, McDowell N, Kaldenhoff R (2008). Function of Nicotiana tabacum aquaporins as chloroplast gas pores challenges the concept of membrane $\mathrm{CO}_{2}$ permeability. Plant Cell, 20, 648-657.

von Caemmerer S, Evans JR (1991). Determination of the average partial pressure of $\mathrm{CO}_{2}$ in chloroplast from leaves of several $\mathrm{C}_{3}$ plants. Australian Journal of Plant Physiology, 18, 287-305.

Warren CR (2004). The photosynthetic limitation posed by internal conductance to $\mathrm{CO}_{2}$ movement is increased by nutrient supply. Journal of Experimental Botany, 55, 23132321.

Warren CR (2008). Stand aside stomata, another actor deserves centre stage: The forgotten role of the internal conductance to $\mathrm{CO}_{2}$ transfer. Journal of Experimental Botany, 59, 1475-1487.

Warren CR, Low M, Matyssek R, Tausz M (2007). Internal conductance to $\mathrm{CO}_{2}$ transfer of adult Fagus sylvatica: Variation between sun and shade leaves and due to free-air ozone fumigation. Environmental and Experimental Botany, 59, 130-138.

Williams TG, Flanagan LB, Coleman JR (1996). Photosynthetic gas exchange and discrimination against ${ }^{13} \mathrm{CO}_{2}$, and $\mathrm{C}^{18} \mathrm{O}^{16} \mathrm{O}$ in tobacco plants modified by an antisense construct to have low chloroplastic carbonic anhydrase. Plant Physiology, 112, 319-326.

Xiong D, Flexas J, Yu T, Peng S, Huang J (2016). Leaf anatomy mediates coordination of leaf hydraulic conductance and mesophyll conductance to $\mathrm{CO}_{2}$ in Oryza. New Phytologist, 213, 572-583.

Xiong D, Liu X, Liu L, Douthe C, Li Y, Peng S, Huang J (2015b). Rapid responses of mesophyll conductance to changes of $\mathrm{CO}_{2}$ concentration, temperature and irradiance are affected by $\mathrm{N}$ supplements in rice. Plant, Cell \& Environment, 38, 2541-2550.

Xiong D, Yu T, Zhang T, Li Y, Peng S, Huang J (2015a). Leaf hydraulic conductance is coordinated with leaf morphoanatomical traits and nitrogen status in the genus Oryza. Journal of Experimental Botany, 66, 741-748.

Yamori W, Nagai T, Makino A (2011). The rate-limiting step for $\mathrm{CO}_{2}$ assimilation at different temperatures is influenced by the leaf nitrogen content in several $\mathrm{C}_{3}$ crop species. Plant, Cell \& Environment, 34, 764-777.

Yamori W, Noguchi K, Hanba YT, Terashima I (2006). Effects of internal conductance on the temperature dependence of the photosynthetic rate in spinach leaves from contrasting growth temperatures. Plant Cell Physiology, 47, 10691080 .

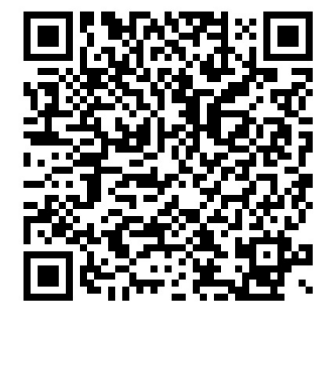

www.plant-ecology.com 